\title{
Oral Submucous Fibrosis Turning Malignant. A case report and review of literature.
}

\author{
Dr. James Solomon Jesudasan, B.D.S, (M.D.S) ${ }^{1}$., Prof.Dr. M.R.Muthusekhar, \\ M.D.S ${ }^{2}$., Prof.Dr. M.F. Baig.(M.D.S) ${ }^{3}$. Dr. P.U. Abdul Wahab. M.D.S, \\ MFDSRCPS, MOMSRCPS ${ }^{4}$.
}

\begin{abstract}
This article describes a male patient who presented with trismus due to submucous fibrosis and how in course of time it turned malignant into oral squammous cell carcinoma. Oral submucous fibrosis (OSF) is a chronic, complex, irreversible, highly potent pre-cancerous condition characterized by juxta-epithelial inflammatory reaction and progressive fibrosis of the submucosal tissues (lamina propria and deeper connective tissues). As the disease progresses, the jaws become rigid to the point that the sufferer is unable to open his mouth. The condition is linked to oral cancers and is associated with areca nut chewing, the main component of betel quid. Areca nut or betel quid chewing, a habit similar to tobacco chewing, is practiced predominately in Southeast Asia and India, dating back thousands of years.
\end{abstract}

\section{Introduction.}

In 1952 Schwartz ${ }^{1,2}$ described five Indian women, from East Africa, with "atrophia idiopathies (tropica) mucosae oris." From India, in 1953, came a report by Joshi"” who coined the term submucous fibrosis of the palate and pillars. Other names that have been suggested are diffuse oral submucous fibros, idiopathic scleroderma of the mouth ${ }^{4}$,idiopathic palatal fibrosis ${ }^{5}$, and sclerosing stomutitis ${ }^{6}$. Submucous fibrosis may be defined as an insidious, chronic disease affecting any part of the oral cavity and sometimes the pharynx. Although occasionally preceded by and/or associated with vesicle formation, it, is always associated with a juxta-epithelial inflammatory reaction followed by a fibroelastic change of the lamina propria, with epithelial atrophy leading to stiffness of the oral mucosa and causing trismus and inability to eat.J. Pindborg, ${ }^{7}$

\section{Case Report:}

A 55 year old male patient reported to the Department of Maxillofacial Surgery, Saveetha Dental College, Chennai in March 2012 complaining of difficulty in opening his mouth and with a complaint of progressive trismus, dysphagia, and oral burning. He noted that over the last 2 to 3 years he had noted increased oral burning, irritation, and progressive difficulty opening his mouth. He denied any other significant medical issue.

He gave a history of chewing tobacco using betel quid 2 to 3 times daily for over 10 years, however, he discontinued this habit 3 months prior to presentation, as his oral discomfort progressed.

On examination, physically the man looked well nourished. Extraoral examination revealed no abnormalities. Intraorally, it was noted that maximal incisal opening was $12 \mathrm{~mm}$. His maxillary and mandibular vestibules were extremely tight, with soft tissue bands running through both vestibules. The unattached gingiva in both vestibules appeared pale and indurated. On further exam, the bilateral buccal mucosa was firm and indurated, with numerous soft tissue bands running vertically. Provisionally a diagnosis of oral submucous fibrosis was given.

At this point the patient was taken to the operation theatre and under general anesthesia surgical excision of the fibrous bands was done bilaterally. Both the vertical and horizontal bands were excised and an immediate mouth opening of $30 \mathrm{~mm}$ was achieved using a Furgeson mouth gag. A small lesion on the right buccal mucosa was noted and excised and sent for histopathological examination. A skin graft from the left thigh was used to close the intra oral wound and held in position by sutures. Post operative mouth opening was $30 \mathrm{~mm}$ on discharge. carcinoma.

The histopathological report of the excised lesion suggested well differentiated squamous cell Radiotherapy was advised and the patient received 15 cycles of radiotherapy.

6 months after radiation the patient reported with a small swelling in the right submandibular region and restricted mouth opening. Examination revealed a solitary swelling that non tender, hard in consistency and fixed to the lower border of the mandible. The skin over the swelling was pinchable. C.T scan revealed a single solitary swelling in the right submandibular region. 
Fig. 1(6 months post radiation with swelling in submandibular region)

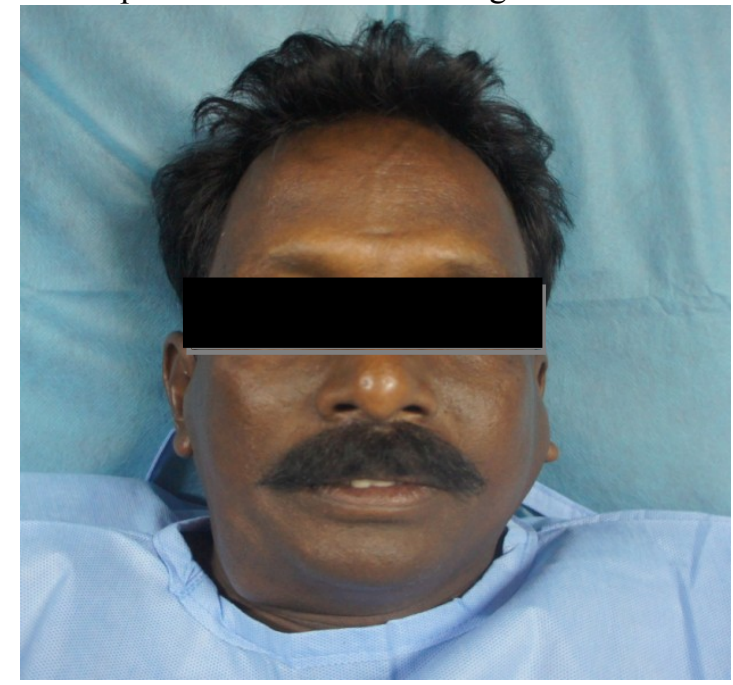

Fig 2.( mouth opening before $2^{\text {nd }}$ surgery)

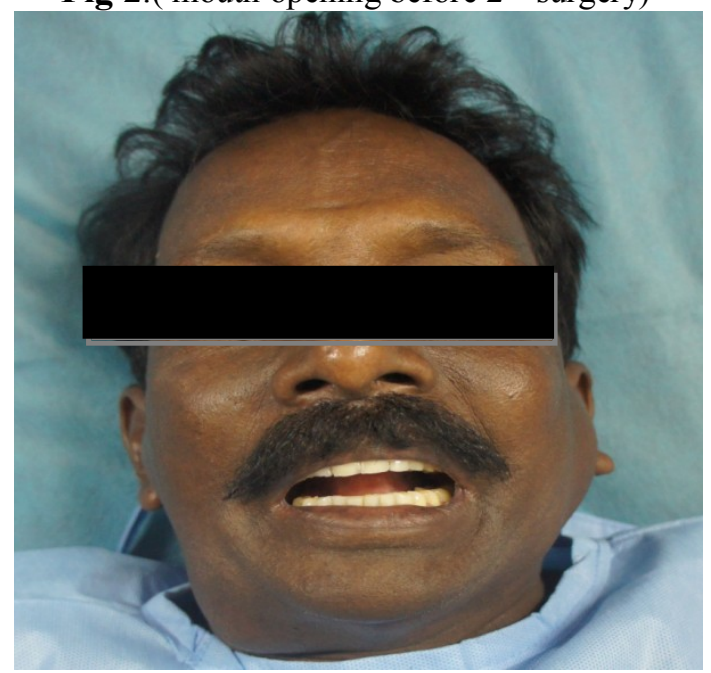

A second surgery was planned under general anesthesia. Radical neck dissection was done and the swelling was removed along with the lower border of the mandible leaving a $2 \mathrm{~cm}$ margin. The patient was discharged on the tenth day postoperatively.

Fig 3. (C.T. showing mass in submandibular region) 


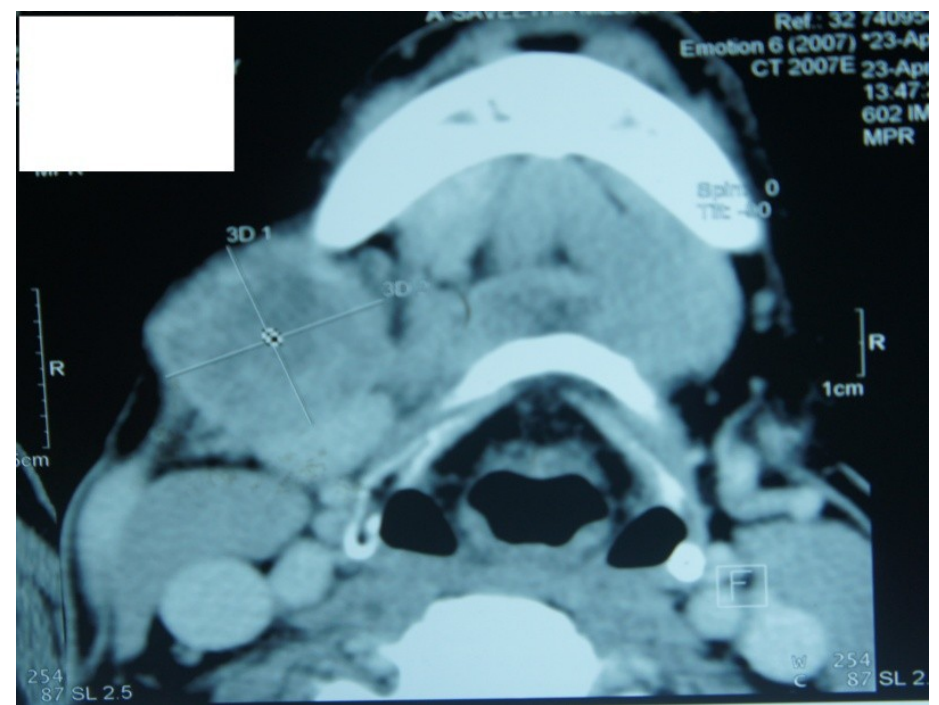

Fig 4. (Intra operative picture after R.N.D and removal of lower border of mandible along with lesion)

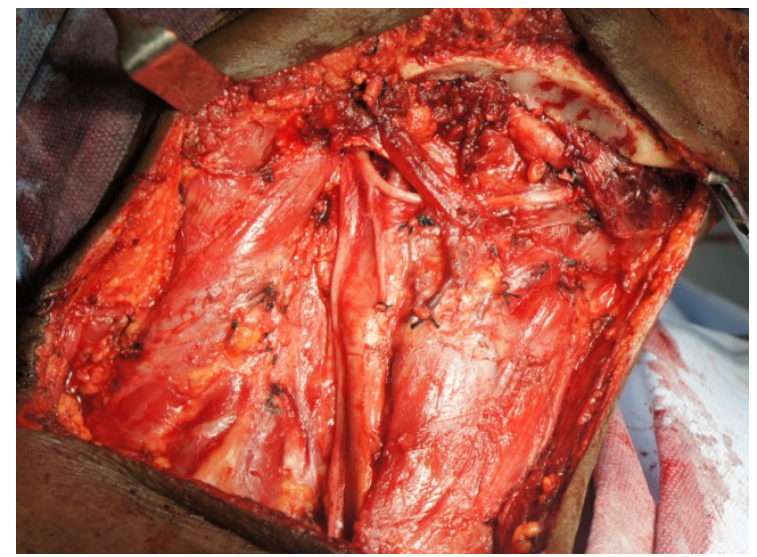

Fig 5.(specimen)

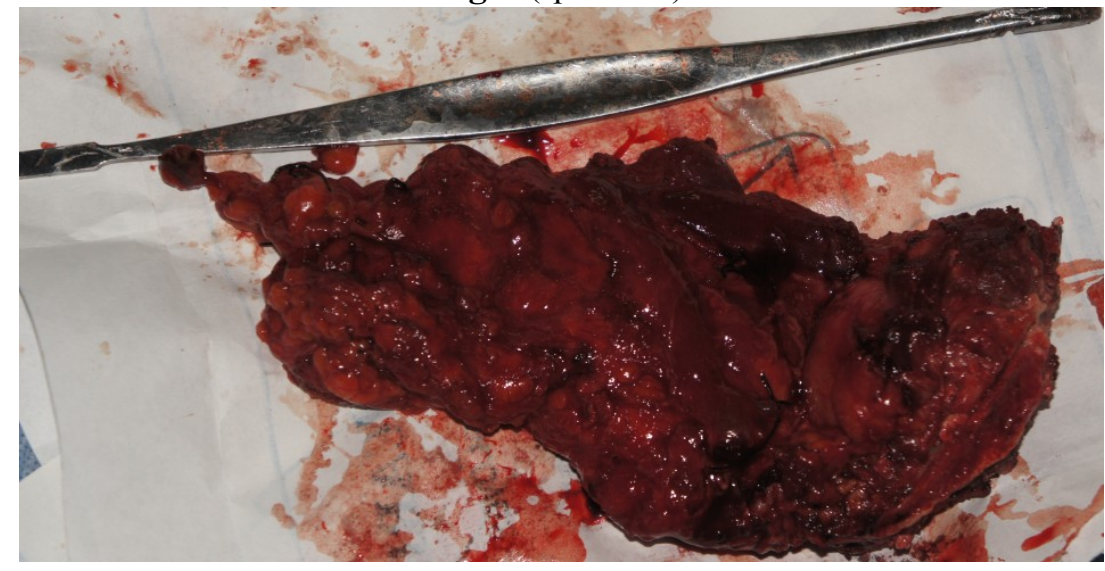

Fig 6.(after closure with skin staples) 


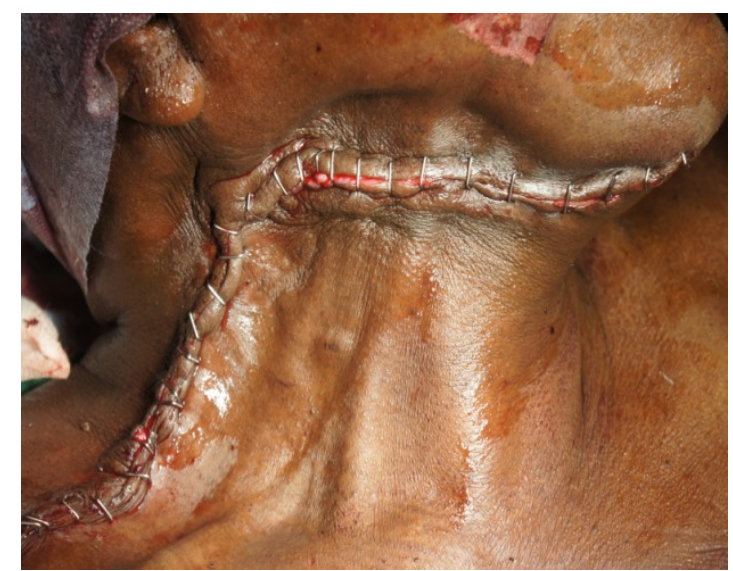

The specimen was sent for histopathological evaluation and revealed the core specimen was suggestive of well differentiated squamous cell carcinoma.

Adequate clearance of the surgical margins was achieved.

\section{Discussion:}

Oral submucous fibrosis is a well-recognised, potentially malignant condition of the oral cavity that can affect any part of the oral mucosa,and is characterised by mucosal rigidity of varying intensity caused by fibroelastic transformation of the juxta-epithelial layer of connective tissue ${ }^{8}$.The presence of palpable fibrousbands is a diagnostic criterion for the disease, and the incidence of malignant change in these patients ranges from $2 \%$ to $10 \%{ }^{9}$. About 2.5 million people are affected world wide, with most cases being in southern India $^{10}$. It occurs in chewers of betel quid in other countries also. There have been several excellent reports on the risks of chewing tobacco. ${ }^{11,12,13,14,15,16}$

The definition by the World Health Organization(WHO) of an precancerous oral condition: "a generalized pathological state of the oral mucosa associated with a significantly increased risk of cancer" fits well with the characteristics of OSMF ${ }^{17,18}$ The condition is thought to be multifactorial in origin with a high incidence in people who chew areca-nut,and a significant malignant transformation rate $(7-30 \%)^{19}$ poses global problems for public health. The physical effects, which include a burning sensation in the mucosa and progressive trismus, can also have psychological and social implications for patients.

\section{SYMPTOMS}

Early symptoms

The onset of the condition is insidious and is often of 2 to 5 years' duration. The most common initial syrnptom is a burning sensation in the mouth, often experienced when the patient is eating spicy food. Other frequent early symptoms are blisters (especially on the palate), ulcerations, or recurrent stomatitis.

Excessive salivation, defective gustatory sensation, and dryness of the mouth can also occur in clinically early stages of the disease ${ }^{4}$.

Later symptoms

After varying periods of time, in some cases a few years after the appearance of the initial symptoms, patients complain of stiffening of certain areas of the oral mucosa, leading to

(I) difficulties in opening the mouth,

(2) in ability to whistle or to blow out a candle, and

(3) difficulties in swallowing ${ }^{19}$.

When the fibrosis reaches the pharynx, the patient may experience referred pain in the ears ${ }^{20}$. The same author finds deafness due to occlusion of the eustachian tubes in one third of the patients $\mathrm{DeSa}^{21}$ and Millard ${ }^{22}$ mention a, nasal voice as one of the later symptoms in some patients.

The initial oral lesion is frequently a non-specific stomatitis which may be accompanied by vesicular eruptions. ${ }^{21,26}$.Occasionally the lesion may mimic the appearance of lichen planus or leukoplakia.Thus, the clinical appearance gives little indication of the underlying disorder and it has been emphasised that a biopsy is required to achieve a definitive diagnosis (Pindborget al., 1980) ${ }^{27,28}$.

The possibility that submucous fibrosis is a precancerous condition arose soon after its initial identification (Paymaster, 1956) ${ }^{23}$. This suspicion has since been substantiated (Pindborg, 1972) ${ }^{24}$ although neoplasia does not appear to develop as frequently as was at first feared.

The use of betel nut has been repeatedly implicated as an etiological factor in submucous Fibrosis ${ }^{2,4}$ but its exact role in the pathogenesis of this disorder is unclear, especially since the disease can occur in the absence of any 
such chewing habit. However, recently reported in vitro experiments ${ }^{29}$ suggest that crude extracts prepared from varieties of areca nut act as potent stimulators of collagen synthesis in human fibroblast cultures. Furthermore, in subsequent in vitro experiments Meghji et al. ${ }^{30}$ showed that tannins from chewed areca nuts reduced the susceptibility of collagen to degradation by collagenase, they concluded that this action might serve also to enhance the development of fibrosis.

A number of studies have characterized smokeless tobacco as an etiological factor in the development of cancer of the oral cavity ${ }^{31,32}$ and the esophagus. One study from Sweden showed that snus dipping (snuff dipping) increased the risk of oral cancer by 5 - to 6 -fold ${ }^{33}$.

As said before OSMF has a malignant transformation rate of $7-30 \%$. ${ }^{19}$ Pathogenesis is thought to be multifactorial.

The carcinogenic effects of tobacco acting in synergy with areca-nut is well known, but the second report on betel quid by the International Agency for Research on Cancer (IARC)identified areca-nut as a "group one carcinogen, ${ }^{34,35,36}$. Its genotoxic and mutagenic effects are attributed to polyphenols, alkaloids, and areca-nutspecific nitrosamines such as N-nitrosoguvacoline, N-nitrosoguvacine, 3-(N-nitrosomethylamino) propionaldehyde, and 3-(N-nitrosomethylamino) propionitrile ${ }^{37}$.Various studies have been conducted in an attempt to identify molecular markers that could be used to predict malignant change in OSMF. Recently, a loss of heterozygosity in 23 "hotspot" loci which alter genes that control the cell cycle has been recognized as an important molecular marker for malignancy in $\mathrm{OSMF}^{34,38}$.

The treatment of submucous fibrosis is at present unrewarding, not least because the pathogenesis of the disease is obscure. Steroid therapy has been utilised with some benefit in early lesions but the effects appear to be transitor $y^{21}$. Surgical excision and skin grafting are applicable where the areas of fibrosis are localised and access unrestricted. A problem arises in the treatment of cases with severe and diffuse fibrosis since it is difficult to secure the release of the mandible through a limited oral approach. In view of this, and given that the fibrosis may recur ${ }^{21}$, surgery has not always been attempted in such cases. Limitations of access are of secondary importance in the presence of concomitant neoplasia as treatment is aimed primarily at tumor eradication and a more aggressive surgical approach is adopted.

\section{Conclusion:}

Like in this particular case if trismus is severe, a comprehensive assessment of the oral mucosa can be difficult and general anesthesia may be required to obtain adequate biopsy specimens. Similarly, the assessment of neoplastic lesions can be hampered and their true extent may not be resolved pre-operatively.

In conclusion, tobacco and areca quid chewing appear to be associated with an increased risk of malignant transformation in OSMF. Most studies regarding oral mucosal lesions underscore the importance of public health strategies targeted toward preventing and reducing exposure to tobacco products and areca quid. The public should be aware of the high risk of oral malignancy in oral precancer lesions induced by consumption of these products.

\section{References:}

[1]. Schwartz, J.: Atrophia Idiopathica (Tropica) Mucosae Oris, Demonstrated at the Eleventh International Dental Congress, London, 1952. (Cited by Sirsat and Khanolkar.: $<0$ )

[2]. Sirsat, S. M., and Khanolkar, V. R.: Submucous Fibrosis of the Palate and Pillars of the Fauces, Indian J. M. SC. 16: 189-197, 1962.

[3]. Joshi, 8. 0.: Submucous Fibrosis of the Palate and Pillars, Indian J. Otolaryng. 4: 1-4, 1953.

[4]. Su, I. P : Idiopathic Scleroderma of the Mouth; Report of Three cases, Arch. Otolaryng.59: 330-332, 1954

[5]. Baa, R. V., and Raju, P. R.: A Preliminary Report on the Treatment of Sul mucous Fibrosis of the Oral Cavity With Cortisone, Indian J. Otolnryng. 6: 81-83, 1954.

[6]. Behl, P. N.: Practice of Dermatology, Bombay, 1962, Allied Publishers Private, Ltd.

[7]. JensJ. Pindborg,SatyavatiM.Sirsat.Oralsubmucousfibrosis Oral Surgery, Oral Medicine, Oral Pathology, Volume 22, Issue 6, December 1966, Pages 764-779

[8]. Aziz SR. Oral submucous fibrosis: an unusual disease. J N J Dent Assoc 1997;68:17-9.

[9]. Pindborg JJ, Mehta FS, Gupta PC, Daftary DK. Prevalence of oralsubmucous fibrosis among 50,915 Indian villagers. Br J Cancer1968;22:646-54.

[10]. Gupta PC, Hebert JR, Bhonsle RB, Sinor PN, Mehta H, Mehta FS. Dietaryfactors in oral leukoplakia and submucous fibrosis in a population-basedcase control study in Gujarat, India. Oral Dis 1998;4:200-6.

[11]. Tilakaratne WM, Klinikowski MF, Saku T, Peters TJ, WarnakulasuriyaS. Oral submucous fibrosis: review on aetiology and pathogenesis. Oral Oncol 2006;42:561-8

[12]. Jacob BJ, Straif K, Thomas G, Ramadas K, Mathew B, Zhang ZF, et al.Betel quid without tobacco as a risk factor for oral precancers. Oral Oncol2004;40:697-704

[13]. Ahmad MS, Ali SA, Ali AS, Chaubey KK. Epidemiological and etiolog-ical study of oral submucous fibrosis among gutkha chewers of Patna,Bihar, India. J Indian Soc Pedod Prev Dent 2006;24:84-9.

[14]. Oakley E, Demaine L, Warnakulasuriya S. Areca (betel) nut chew-ing habit among high-school children in the Commonwealth of the Northern Mariana Islands (Micronesia). Bull World Health Organ2005;83:656-60.

[15]. Ranganathan K, Devi MU, Joshua E, Kirankumar K, Saraswathi TR. Ora lsubmucous fibrosis: a case-control study in Chennai, South India. J OralPathol Med 2004;33:274-7.

[16]. Lee CH, Ko YC, Huang HL, Chao YY, Tsai CC, Shieh TY, et al. The precancer risk of betel quid chewing, tobacco use and alcohol consump-tion in oral leukoplakia and oral submucous fibrosis in southern Taiwan.Br J Cancer 2003;88:366-72.

[17]. Rajendran R. Oral submucous fibrosis: etiology, pathogenesis, and future research. Bull World Health Organ 1994;72:985-96.

[18]. World Health, Organization. Guide to epidemiology and diagnosis oforal mucosal diseases and conditions. Community Dent Oral Epidemiol1980;8:1-26.6. 
[19]. Aziz SR. Oral submucous fibrosis: case report and review of diagnosis and treatment. J Oral Maxillofac Surg 2008;66:2386-9.

[20]. Rao, A. H. N.: Idiopathic Palatal Fibrosis, Brit. .J. Surg. 50: 23-25, 1962

[21]. DeSa, J. V.: Submucous Fibrosis of the Palate and Cheek, Ann. Otol. Rhin. \& Laryng. 66: 1143.1159, 1957.

[22]. Millard, P. R.: Submucous Fibrosis, Brit. J. Dermat. 78: 305-307, 1966

[23]. Paymaster, J. C. (1956). Cancer of the buccal mucosa. Cancer, 9, 431.

[24]. Pindborg, J. J. (1972). Is submucous fibrosis a precancerous condition in the oral cavity. International Dental Journal, $22,474$.

[25]. M. McGurk, * and G. T. Craig Oral Submucous Fibrosis: Two cases of malignant transformation in Asian immigrants to the United Kingdom .British Journal of Oral and Maxillofacial Surgery (1984) 22, 56-64,

[26]. Pindborg, J. J. \& Singh, B. (1964). Formation of vesicles in oral submucous fibrosis.Acta Pathology and Microbiology Scandinavica, 62, 562.

[27]. Pindborg, J. J. (1980a).Oral Cancer and Precancer. 1st Edn., p. 111. John Wright and SonsLtd., Bristol.

[28]. Pindborg, J. J. (1980b). 'Lesions of the oral mucosa to be considered premalignant and their epidemiology'. In I. C. Mackenzie, E. Dabelsteen, and C. Squier, (Eds.); Oral Premalignancy. 1st Edn., p. 10. University of Iowa Press, Iowa.

[29]. Caniff, J. P. \& Harvey, W. (1981). The aetiology of oral submucous fibrosis: The stimulation of collagen synthesis by extracts of areca nut. International Journal of Oral Surgery, 10, 163

[30]. Meghji, S., Canniff, J. P., Harvey, W., Scutt, A. \& Phillipson, D. (1982). Inhibition of collagenase activity by areca nut tarmis: a mechanism of collagen accumulation in oral submucous fibrosis. Journal of Dental Research, 61, 545 (abstract 89).

[31]. Agency for Research on Cancer. Tobacco habits other than smoking; betel-quid and areca-nut chewing; some related nitrosamines. International Agency for Research on Cancer Tobacco. Lyon: IARC monographs on the evaluation of carcinogenic risks to humans, 1985.

[32]. Statement NC. Health implications of smokeless tobacco use.Bethesda, MD: National Institutes of Health; 1986.

[33]. Idris AM, Ibrahim SO, Vasstrand EN, et al. The Swedish snus and the Sudanese toombak: are they different? Oral Oncol 1998;34:558-66

[34]. Angadi PV, Rao SS. Areca nut in pathogenesis of oral submucous fibrosis:revisited. Oral Maxillofac Surg 2011;15:1-9.11

[35]. Murti PR, Bhaonsle RB, Pindborg JJ, Daftary DK, Gupta PC, Mehta FS.Malignant transformation rate in oral submucous fibrosis over 17yearperiod. Community Dent Oral Epidemiol 1985;13:340-1.

[36]. Nair U, Bartsch H, Nair J. Alert for an epidemic of oral cancer due to useof the betel quid substitutes gutkha and pan masala; a review of agentsand causative mechanisms. Mutagenesis 2004;19:251-62.

[37]. Mathur RM, Jha T. Normal oral flexibility—a guideline for OSMF. JIndian Dent Assoc 1993;64:139-43..

[38]. Teh MT, Tilakaratne WM, Chaplin T, et al. Fingerprinting genomic insta-bility in oral submucous fibrosis. J Oral Pathol Med 2008;37:4306 . 